\title{
Special Needs Adoption and Foster Exigencies (SAFE): A Model for Case Managers
}

\author{
Kristen F. Linton \\ Andrea Birmingham \\ Loren Case \\ Laura Ezzy \\ Jandee Ferguson \\ Courtney Harrison \\ Leina'ala Launiu
}

\begin{abstract}
Children with special needs disproportionately receive child welfare services in out-of-home placements, such as foster and adoptive homes. This theoretical model has been developed to describe or explain exigencies of adoptive and foster families of children with special needs $(n=82)$. A web content analysis, including theme, feature, link, exchange, and language analyses, of online discussion forums of adoptive and foster parents of children with special needs using a phenomenological framework was conducted. Inductive and quantitative web content analyses were conducted on themes. Parenting concerns were clustered into two main themes, disability and placement issues, and focused on children's pre and post placement needs. A phenomenological analysis resulted in the development of the Special Needs Adoption and Foster Exigencies (SAFE), which outlines exigencies of adoptive and foster parents of children with special needs during engagement, assessment, and intervention phases of case management.
\end{abstract}

Keywords: Special needs, adoption, foster, case work

Children with special needs (e.g., disabilities) disproportionately receive child welfare services (Hill, 2012). They are also more likely to receive services longer and in out-ofhome placements (Lightfoot, Hill, \& LaLiberte, 2011). Minimal research on adoptive and foster families that care for children with disabilities has found that they have special needs related to case work, interventions, and school (Geenen \& Powers, 2004; Manders \& Stoneman, 2009; Raghavan, Inoue, Ettner, Hamilton, \& Landsverk, 2010). Child welfare case workers may need additional training in order to meet the needs of adoptive and foster families of children with special needs. However, no previous theoretical model has been developed to describe or explain exigencies of adoptive and foster families of children with special needs.

\section{Prevalence of Children with Special Needs in Child Welfare}

Children with disabilities are more likely to be involved in the child welfare system than other children (Lightfoot et al., 2011; Sullivan \& Knutson, 2000). An elaborate study that merged state, school, child welfare, and police records found that there was a nine

Kristen F. Linton, MSW, Ph.D., is an Assistant Professor, and Andrea Birmingham, Loren Case, Laura Ezzy, Jandee

Ferguson, Courtney Harrison, and Leina'ala Launiu are MSW Candidates, all in the Myron B. Thompson School of Social Work at the University of Hawai'i at Manoa.

Copyright (C) 2014 Advances in Social Work Vol. 15 No. 2 (Fall 2014), 334-351 
percent prevalence rate among nondisabled children and $31 \%$ prevalence rate among disabled children for substantiated child maltreatment (Sullivan \& Knutson, 2000). Another study using child welfare administrative data found that $22 \%$ of children with substantiated maltreatment were labelled as having a disability in their case files suggesting that one out of every fifth child with substantiated abuse on a child welfare case load may experience disabilities. Most commonly, children were diagnosed with emotional disturbance. Other diagnoses included intellectual, developmental, and learning disabilities (Lightfoot et al., 2011).

Children with special needs are more likely to receive out-of-home services longer and experience instability. Hill (2012) found that youth with disabilities were in out-of-home placements longer $(M=24.7$ months compared to $M=21.4$ months for no disability) than other children. Youth with disabilities also had a higher average number of out-of-home placements in two studies ranging from four to five and a half placements for children with disabilities compared to three to four and a half placements for children without disabilities on average (Hill, 2012; Slayter \& Springer, 2011). Out-of-home placement and instability may be associated with the decreased likelihood that children with disabilities have a permanency plan with a goal of reunification for various reasons. Children with disabilities were more likely to have different types of placements than their peers in two studies (Slayter \& Springer, 2011; Hill, 2012). Slayter and Springer (2011) found that children with disabilities were $49 \%$ less likely to be placed with families in a trial home, $61 \%$ less likely than peers to be placed in kinship care, and two-times more likely to be living in non-kinship care or a pre-adoptive foster home.

\section{Needs of Adoptive and Foster Parents of Children with Special Needs}

Adoptive and foster families caring for children with disabilities have special needs associated with case work, interventions, and school. Scant research exists about case workers' support of children with special needs. A recent study shed light on case workers' perceptions of cases with children with disabilities using vignettes (Manders \& Stoneman, 2009). Manders and Stoneman (2009) found that 75 child welfare case workers were more likely to attribute abuse to child characteristics rather than parent characteristics, have empathy for parents, and suggest child-focused rather than parent-focused services when responding to vignette cases of maltreatment among children with disabilities. This powerful study demonstrated that case workers perceive cases with children with disabilities differently (e.g., child characteristics contributed to abuse and more empathy for parents) and plan to respond to cases differently (e.g., child-focused services) than they would for children without disabilities.

Children receiving child welfare services are more likely to need mental health interventions. The Child Welfare League of America, The American Academy of Pediatrics, and American Academy of Child and Adolescent Psychiatry recommend that children should receive a mental health screening when they are placed in foster care, a subsequent comprehensive mental health assessment, and a coordinated approach to delivery of mental health services. Only half of the children in a sample of 3,802 children receiving child welfare services were receiving any one of the recommendations (Raghavan et al., 2010). However, research has also demonstrated that children receiving 
child welfare services are more likely to use antipsychotic medications. Youn, Rubin, Riddle, Noll, and Rothbard (2011) found that children in foster care were more likely to be taking more than one antipsychotic medication for more than 180 days (19-24\%) than children who were not in foster care (less than 15\%) in a sample of 16,969 youth aged 20 or younger.

Children with disabilities are more likely to struggle in school and receive special education services. A study of 327 children found that children in foster care had significantly lower GPAs, changed schools more frequently, earned fewer credits toward graduation, had significantly lower state test scores, and had greater difficulty in reading and math (Geenen \& Powers, 2004). A strong correlation has been found between children's receipt of child welfare and special education services (Algood, Hong, Gourdine, \& Williams, 2011; Jonson-Reid, Drake, Kim, Porterfield, \& Han, 2004). Interestingly, one study found that child welfare involvement predated children's receipt of special education services (Jonson-Reid et al., 2004). This study only reports that children began receiving special education services after child welfare services. Children could have had a disability prior to receiving special education. Increased special education may be a result of education and advocacy among case workers and/or parents.

Children with special needs are more likely to receive child welfare services longer than other children and be placed with non-kinship foster families (Lightfoot et al., 2011; Slayter \& Springer, 2011). Children with special needs have additional needs associated with case work, interventions, and school than other children (Bean \& Sidora-Arcoleo, 2012; Geenen \& Powers, 2004; Manders \& Stoneman, 2009; Raghavan et al., 2010). Therefore, adoptive and foster parents of children with special needs may have unique exigencies. This study aimed to develop a theoretical model, Special Needs Adoption and Foster Exigencies (SAFE), to better describe the needs of adoptive and foster parents of children with special needs. A web content analysis was used to understand themes in parenting concerns and advice given among adoptive and foster parents of children with special needs' online discussions. These themes were used to begin to develop SAFE. Child welfare case workers can use SAFE as a guide to learn about the exigencies of adoptive and foster parents of children with special needs and prioritize services and resources for those families.

\section{Methods}

\section{Data Collection}

Parenting concerns among adoptive and foster parents of children with special needs were collected from posts on Forums.Adoption.com, a popular online discussion forum used by adoptive and foster parents. The University of Hawaii at Manoa Institutional

Review Board determined that this study was exempt. Online data, such as those in discussion boards, are considered public data if no password is needed to access the data. No passwords were required to access the data used for this analysis. The discussion forum was chosen based on Google search terms: adoption, foster, special needs, discussion, and forum. This site was chosen because its members were primarily from the U.S. and it had a large membership. A total of 223,200 members had participated in 396,527 threads and 
2,881,276 posts on Forums.Adoption.com at the time of data collection suggesting a large, active membership. A sub-forum on Forums.Adoption.com was selected titled, "Special Needs and Attachment." Under the "Special Needs and Attachment" sub-forum, the most common forum was titled, "Special Needs Adoption." For clarification, data for this analysis was found by going to the Forums page, then selecting the category, "Special needs and attachment," and then selecting the sub-category "Special needs adoption." This forum was chosen to gather data on parenting concerns among adoptive and foster parents of children with special needs only. Other forums under "Special Needs and Attachment" were specific towards certain diagnoses, such as Autism. In addition, the "Special Needs Adoption" forum chosen for analysis included 11,310 threads and 110,310 posts at the time of data collection. Other forums under "Special Needs and Attachment" had significantly lower thread and post counts with a maximum of 670 threads and 5,264 posts suggesting that the forum chosen for analysis was the most popular discussion forum on special needs on the Forums.Adoption.com site.

The first author read through the "Special Needs Adoption" forum from the most recent threads. The first author consulted the data for themes and determined that saturation, or redundancy of information, was met in the threads that were most recently posted between July 1, 2013 and August 31, 2013 (Padgett, 2008). Twenty-six threads and 163 posts were analyzed.

\section{Sample}

A total of 82 adoptive or foster parents of children with special needs participated in the analyzed discussion threads. Participants self-identified their gender as female $(\mathrm{n}=80$; $93 \%)$ and male $(\mathrm{n}=4 ; 4.8 \%)$; two participants did not specify their gender $(2.3 \%)$. Participants reported that they were from 31 U.S. states, while one woman reported that she was from Europe and another reported she was from Canada. The most common states that participants were from were California $(n=6)$, Texas $(n=6)$, Ohio $(n=4)$, Alabama $(n=3)$, Connecticut $(n=3)$, Illinois $(n=3)$, Maine $(n=3)$, Maryland $(n=3)$, New Jersey $(\mathrm{n}=3)$, and Washington $(\mathrm{n}=3)$. One to two participants were from: Arizona, Colorado, Florida, Hawaii, Idaho, Indiana, Kansas, Kentucky, Massachusetts, Michigan, Minnesota, Missouri, New Hampshire, New York, Oklahoma, Oregon, Pennsylvania, Tennessee, Utah, Virginia, and Wisconsin. Participants self-reported their roles as adoptive parents (n $=63 ; 73.3 \%)$, foster parents $(\mathrm{n}=13 ; 15.1 \%)$, and people who were adopted $(\mathrm{n}=4 ; 4.7 \%)$. The total, mean, standard deviation, minimum and maximum number of posts, child placements, boy placements, and girl placements for the sample participants are displayed in Table 1.

\section{Analysis}

Web content analysis (WCA) of a leading online discussion community of adoptive and foster parents was performed. As described by Herring (2010), WCA includes many similar aspects to content analysis including image and theme analysis (Krippendorff, 2008). It also includes feature, link, exchange, and language analysis to demonstrate the multimodal capabilities, or characterization of many different modes of activity or occurrence, available to users during online discussions (Herring, 2010). This study 
included all aspects of WCA with the exception of image analysis, because no images were posted on the discussion forum used for analysis.

Table 1. Descriptive Statistics of Posts and Themes

\begin{tabular}{lccccc}
\hline & $\boldsymbol{N}$ & $\boldsymbol{M}$ & $\boldsymbol{S D}$ & Min & Max \\
\hline Total posts & 296 & 3.44 & 3.92 & 1 & 19 \\
Total placements & 195 & 3.98 & 6.10 & 0 & 27 \\
Total girls & 53 & 1.66 & 2.51 & 0 & 13 \\
Total boys & 57 & 1.58 & 2.61 & 0 & 15 \\
Disability & 117 & 1.36 & 1.42 & 0 & 7 \\
Intervention & 75 & 0.87 & 1.41 & 0 & 9 \\
Empathy & 61 & 0.71 & 1.32 & 0 & 7 \\
Placement & 39 & 0.45 & 1.04 & 0 & 6 \\
Resources & 39 & 0.45 & 1.18 & 0 & 7 \\
School & 33 & 0.38 & 0.77 & 0 & 3 \\
Case Worker & 20 & 0.23 & 1.04 & 0 & 9 \\
Physiological & 14 & 0.16 & 0.63 & 0 & 4 \\
Historical Information & 9 & 0.10 & 0.34 & 0 & 2 \\
Parental Social Support & 7 & 0.08 & 0.56 & 0 & 5 \\
\hline
\end{tabular}

Theme analysis was conducted with inductive content analysis and quantitative content analysis (Ryan \& Bernard, 2003; Nimrod, 2009). The first author created a set of codes after reading through all text. The codes were revised after reading through the text a second time. One or more codes could be assigned to every segment of text. Multiple codes were subsumed by larger categories or themes. A codebook describing the themes was created. Six graduate student researchers coded the text. Three researchers were assigned to the first half of the text and three researchers were assigned to the second half of the text. They coded their assigned text using the codebook to assess inter-rater reliability. A kappa of .72 for the first half of the data and .82 for the second half of the data was reached suggesting good agreement among the coders (Orwin, 1994). $K$ is a measure widely used for agreement (Orme \& Gillespie, 1986; Viera \& Garrett, 2005). The $k$ values in this study refer to agreement between the six raters on a total of 193 statements. This use of the $k$ is similar to that in other previous phenomenological research (Linton, Krcek, Sensui, \& Spillers, 2013).

Quantitative content analysis was conducted following inductive content analysis. Sample demographic information and theme information were entered into SPSS V.19. Demographic information available included gender, state, and total number of child 
placements, boy placements, and girl placements. Theme information included the number of times that each participant posted on a certain theme. The frequency of posts regarding each theme was analyzed first. Dichotomous variables were created to demonstrate whether or not participants discussed each theme.

Feature, link, and exchange analysis were used to provide context to the additional information available to the participants as they engaged in discussion. Feature analysis was conducted by viewing the "Special Needs Adoption" forum page. The author counted and described the advertisements and sidebars. Link analysis included reading through all data and copying hyperlinks to a separate document. The author counted the hyperlinks and described the main theme(s) of the links. Exchange analysis included counting the times that participants mentioned continuing discussion elsewhere, e.g., using private messages.

Language analysis was used to assess emotion words associated with the themes. Balog, Mishe, and de Rijke (2006) conducted correlational analysis between the uses of emotion words, such as "excited," "worried," or "sad," with discussion of world events among blog users. Similarly, the methodology utilized in this study searched for emotion words described throughout all discussion text. The theme discussed while using the emotion word(s) was described. The emotion words and their corresponding themes were described to demonstrate emotions associated with each theme.

\section{Results}

\section{Theme Analysis}

The final codebook resulted in ten themes related to parenting concerns: disability, placement, school, physiological versus psychological symptoms, lack of historical information, parental social support, case workers, interventions, and empathy (Table 1). Cross tabulations and chi-square statistics indicated that the discussion of the following themes were correlated with each other: 1) placement, case worker, empathy, lack of historical information, and social support and 2) disability, interventions, school, resources, and physiological versus psychological (Figure 1 and 2). The focal areas of discussion fit into the initial steps of the social work practice framework: engagement, assessment, and intervention. Placement concerns and topics associated with placement were primarily related to engagement and assessment. Disability concerns and topics associated with disability were primarily related to assessment and intervention. Parents focused their engagement discussion on their relationships with child welfare case workers. Participants made recommendations about assessing appropriate placements and receipt of disability diagnosis assessments, which included differentiating between psychological or physiological diagnoses. They also reported that they often lacked historical information on adoptive and foster children that could help them to understand and receive appropriate assessments of their child. Parents recommended interventions for specific disabilities as well as provided advice on adaptations to the educational experience of children with special needs. Pseudonyms are used to refer to participants to ensure confidentiality. 
Figure 1. Statistically Significant Correlations Between Disability, Interventions, School, and Resources Themes $(p<.05)$

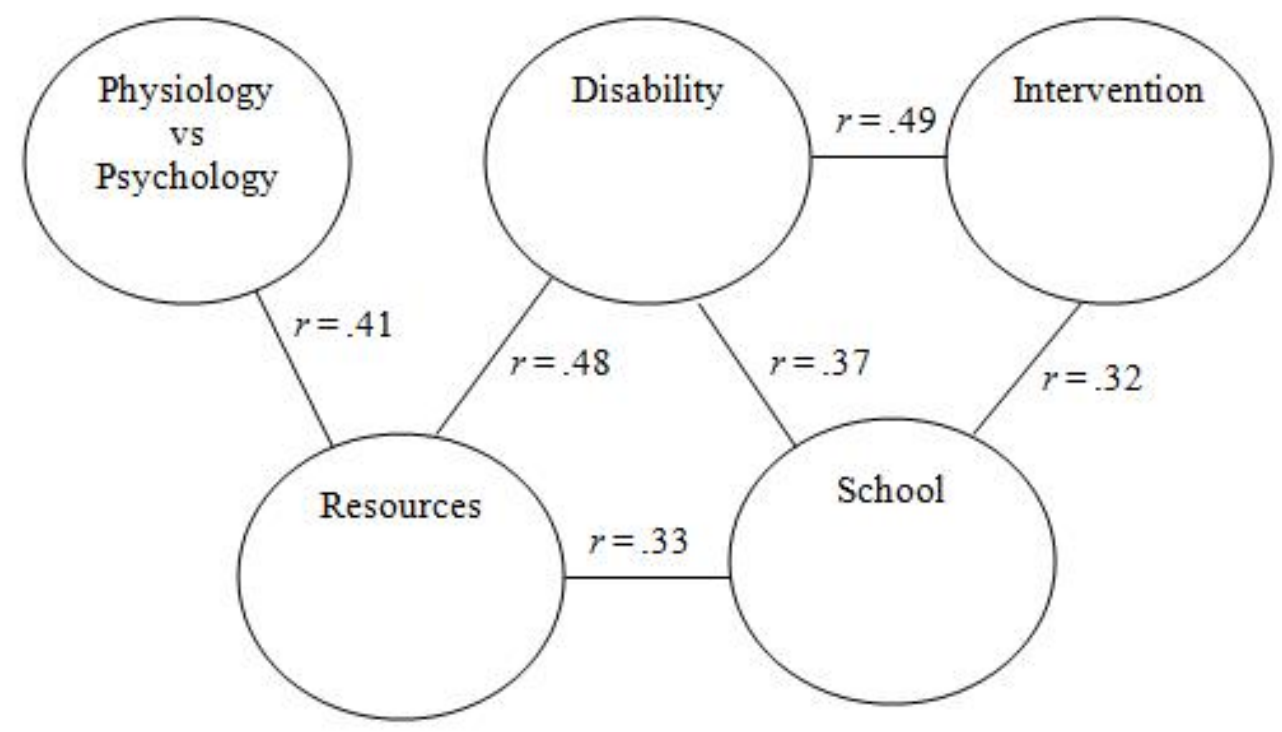

Figure 2. Statistically Significant Correlations Between Placement, Case Worker, History, Empathy, and Social Themes $(p<.05)$

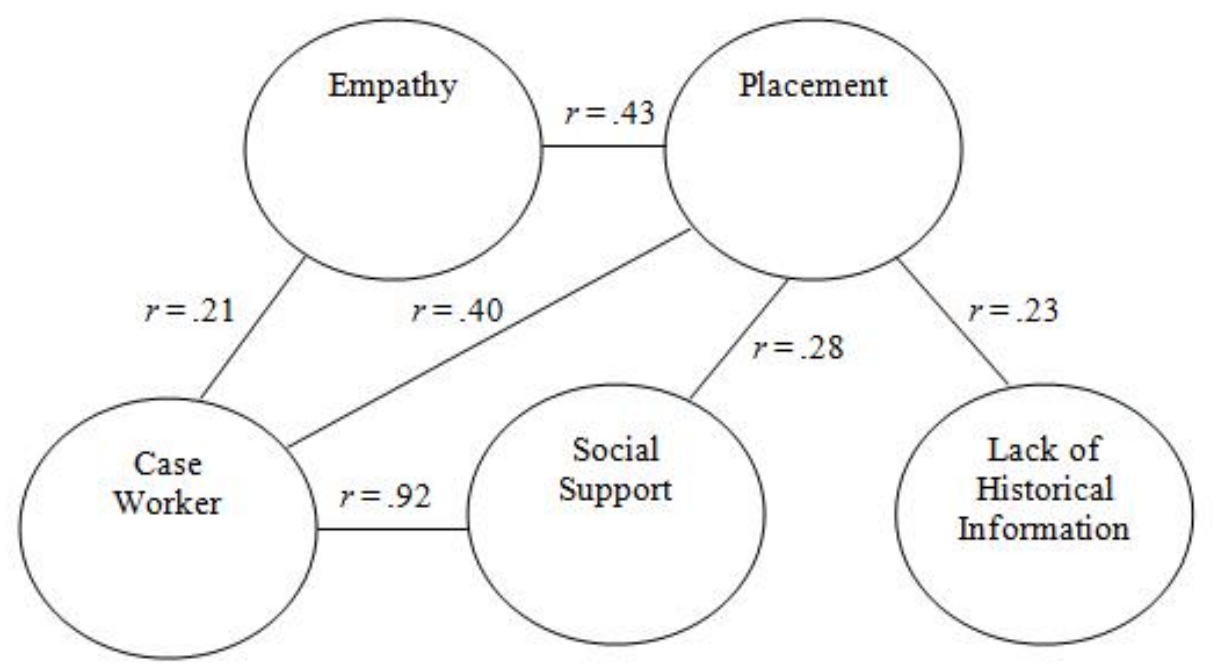

\section{Engagement}

The only aspect of engagement discussed by parents was their relationship with child welfare case workers. Four adoptive and foster parents reported that case workers are "notorious for taking time to respond" to emails and phone calls of inquiries. Kandy, an adoptive mother of four from Oregon explained, "I remember giving up hope on certain 
inquiries and hearing weeks later from the child's case worker." The only advice given by parents was to be patient and "hang in there" while waiting for responses. In addition, other participants expressed concerns that case workers were not supportive of them. For example, one parent expressed, "I guess our worker is pissed at us because she went to town on the stand."

\section{Assessment}

Placement Assessment. Potential adoptive and foster parents sometimes questioned whether they were appropriate placements for children with special needs. Placement assessments were discussed in the context of the potential adoptive or foster child's disability and severity of the child's disability. The following disabilities were discussed concerning placement decisions: Hydrocephalus, West Syndrome, Fetal Alcohol Syndrome (FAS), Reactive Attachment Disorder (RAD), Mental Retardation (MR), and co-occurring disorders. Hydrocephalus and West Syndrome were only discussed by one parent with advice given by two others. Jenny, a foster mother of seven children from Texas, reported: "We're considering submitting our home study for a girl we found through the state photo listing. She is 4 and has the following diagnosis: West Syndrome, Static Encephalopathy, cortical blindness, and Hydrocephalus." Regarding the child's Hydrocephalus diagnosis, Taylor, an adoptive mom of five children, urged Jenny to be: "most concerned on what damage was caused to the brain before the shunt was placed or during placement. It could range from no damage to severe." Providing advice to another parent regarding a placement of a child with West Syndrome, Leilani, a foster parent of two children from Maryland expressed that: "West syndrome is a severe epilepsy syndrome, with a poor prognosis. The majority of children with it will have severe mental retardation, often with psychiatric or behavioral problems as well. The seizures tend to be very difficult to control with medications."

Helga, an adoptive mother of three from California, asked other parents about their knowledge of adopting a 10-year old girl with FAS and ADHD (Attention-Deficit Hyperactivity Disorder). She reported that she and her husband are "pros" at ADHD, but had no experience with FAS. Five other parents reported that there were two main aspects to the diagnosis to consider: learning difficulties and impulse control. Amy, a foster mother of two, demonstrated the learning difficulties:

My first son has been diagnosed with FAS... He is a joy. Yes, it does take longer for a FAS child to learn things, but once they get it, they have it. My son...will attend 1/2 day Kindergarten and 1/2 day 1st Grade. This will allow him to get 11/2 yrs each of kinder and 1st grade. That will give him the best chance for success in school because by then he will have had the chance to get his ABC's and 123's down pat. He also has a great deal of trouble with his fine motor skills so it will also let him have that extra year of learning/practicing to write and start to read.

An adoptive mother, Jacqueline, illustrated potential issues with impulse control experienced by children with FAS: "At 16, he would still walk out into the street without a thought of looking for cars." 
An adoptive and foster mother of 27 children over time, Nancy, expressed concern about possible foster placement with an 11-year old girl with RAD whom she previously fostered but ultimately disrupted due to Nancy's belief that the child contributed to breaking up Nancy's relationship. Nancy also had two other teenage children with autism in her home. Rose, an adoptive mother of one child concurred with Nancy's assumption that the child contributed to her relationship breakup and warned against it happening again: "she'll likely divide and attempt to conquer. I wouldn't take any kids older than mine-especially if they're small and she's volatile." Another mother suggested that the 11-year old with RAD should be the only child in a home. Another foster and adoptive mother of 27 children from Connecticut had very strong, negative feelings about children with RAD: "I've been dealing with a kid with RAD for 14 yrs and the things she has put us through I wouldn't wish on my worst enemy...RUN!"

A potential adoptive mother from Pennsylvania, Lilly, was concerned about adopting a child with PTSD (Post-Traumatic Stress Disorder), bi-polar disorder, ADHD, and an IQ score of 72. Lilly was mostly concerned about the child's IQ score in consideration of adopting the child. Two other parents suggested to Lilly that IQ is a subjective measurement of intelligence. Monica, an adoptive mother of a child with borderline MR recommended:

72 is borderline...IQ tests are not always reliable with kids like ours [with cooccurring disorders]. My son tests very low, but in reality, there's no way a child with an IQ score as low as his would be able to learn as quickly as he does. He has PTSD and anxiety, so any sort of testing is pretty unreliable for him. He also has poor visual and auditory processing skills due to early neglect/possible substance abuse. But, his skills have increased so significantly with less than 2 years of interventions, I think that eventually he will function much more independently. Honestly, his remaining behavioral/mental health issues impact him WAY more than any cognitive deficits.

Social Support. Adoptive and foster parents often discussed their need for social support throughout the placement assessment process. Typically, the discussions of social support were regarding spousal emotional support. An example of this is Susan, an adoptive mother from Hawaii, whose parenting challenges with an adoptive child with RAD were causing marital conflict. Susan expressed, “....my husband doesn't come to therapy, it is just her and I cause him and her are just fine. I am the evil one...we had a knock down drag out tonight so I don't know about the marriage." Another mother, Natia, empathized with Susan and encouraged her to address her marital concerns:

This kind of stuff isn't uncommon when it comes to RAD and marriage. The mother figure is ALWAYS the one to receive the worst of everything, period. The bigger issue would seem to be your marriage.... I think someone awhile back suggested marriage counseling for just the two of you...is that totally out of the question?

Lack of Historical Information. While the parents above had information about children, other parents reported that they lacked information about children's medical, disability, and sexual abuse history prior to or after placement. Yasura, an adoptive mom of three from New Jersey, expressed: "Ugh. I wish I knew what went on while he [my son] 
was in foster care. The family seemed nice enough when we picked him up. Or maybe his mom abused drugs. Or it could just be genetic. We'll never know." Discussed in context with specific disabilities, three parents felt that child welfare case workers intentionally did not give out information about disabilities, behaviors, and experiences of children. An adoptive mother of one from Washington, Mia said, "RAD [Reactive Attachment Disorder] is hard...I hate hate hate it that caseworkers do not give this information to foster parents. I hate hate hate that they sugarcoat it and end up doing so much damage to the foster parents and to the children they are supposed to be helping." Lacey, an adoptive mom from Pennsylvania, expressed:

To be honest I think some agencies downright lie and omit things that foster parents should be made aware of --sexual abuse is one of them. Some kids can talk about sexual abuse they experienced and get through it and others internalize it and end up becoming sex offenders themselves. --I think this is one reason agencies are less than upfront about sexual abuse- they know it is going to make it much more difficult to find placement for a child who is acting out sexually-especially if it's a boy.

Disability Assessment. After families began to foster or had adopted children, they wanted to learn more about their children's disabilities. General disability diagnosis discussions focused on obtaining educational and neuropsychological assessments. Advice included obtaining the right assessments and finding the right person to conduct the assessment. Participants reported that educational and neuropsychological assessments are different based on the process of requesting assessments, what information is provided for the assessments, and cost. Monica, an adoptive mother of one child from Ohio, explained:

Educational testing can be requested in writing.... This testing needs to be educationally-relevant--for example, cognitive testing, functional performance testing (how she actually uses her cognitive skills), speech and language testing, etc.... Most districts will not complete assessments for mental illness, etc., as they aren't really qualified. You may be able to request help from your county board of developmental disabilities or from a local mental health recovery board for a neuropsych assessment. Neuropsych testing is expensive.

Another adoptive mom of one from Massachusetts informed other parents that it is important to find the right neuropsychologist to perform the assessment. Cynthia advised parents to ask the neuropsychologist initial questions:

The questions you should ask should relate to what you suspect are your kiddo's issues -- and making sure the neuropsych has knowledge/expertise in that area. And that the $\mathrm{np}$ [neuropsychologist] can write a report that will get you what you need for kiddo (referral to therapy, IEP with the school, etc.)

Physiological Versus Psychological Symptoms. Physical and psychological comorbidity or the possibility of co-morbidity assessment was a difficult challenge discussed by parents of children with special needs. Sometimes parents could not differentiate between the symptoms of psychological and physical health conditions. For example, an experienced adoptive mother of five children, Taylor, reported the following story about 
her son with autism, "I got a call Friday from [my son's] school. He was sitting in circle time, his nurse was watching and all of the sudden his body went ridged and his eyes rolled back into his head... EEG (electroencephalogram) came back normal." Other parents shared similar experiences of children who exhibit seizure-like behaviors that could be associated with a psychological diagnosis, such as "stimming" in autism. They reported that some seizures do not show up on EEGs. Other typical assessments could include CT (Computed Tomography) scans and taping seizures and showing the tape to a neurologist. Taylor shared an unorthodox assessment given to her by her neurologist:

...real test is that if you can "snap him out of it," it isn't a seizure. So here we go with the oddest script I have ever seen.... If he does either of the behaviors, (hands by face or eyes rolling back) we are to tickle him. Yep, that's right. I have a script ordering us to tickle [my son].

\section{Intervention}

Advice on interventions was given for specific diagnoses including Apraxia, ADHD, Cerebral Palsy (CP), Dyslexia, FAS, PTSD, and Reactive Attachment Disorder (RAD). It should be noted that $52 \%$ of the intervention-themed posts discussed medication use to address children's disabilities. Only one person recommended an intervention for Apraxia. Victoria, an adoptive mother from Oklahoma, reported that her daughter "works with a speech pathologist who is helping her find ways to access the missing words, and to communicate while multi tasking. For example, she can't talk and complete a project with her hands at the same time."

ADHD interventions were discussed frequently among adoptive and foster parents. Recommendations for interventions were divided into medication and alternative interventions. Eight parents reported medications that worked as Metadate and Tenex as a combination, Adderall, Concerta, Daytrana, and Intuniv. They also reported those that did not work as Vyvanse, Strattera, and Intuniv. Parents reported that Vyvanse caused a child to have a negative mood, Strattera caused a child to be like a "zombie," and Intuniv did not do anything. Andy, an adoptive mother of two children, who reported that Intuniv worked for her child, clarified that it took a while to show an effect. Monica, an adoptive mother with a son with ADHD from Ohio expressed her success with alternatives to medication, "Several doctors that we have seen immediately wanted to throw medication at [my son]...If we had agreed, I really don't think we would have seen the HUGE changes in him that we've seen so far." Monica and 11 other parents suggested the following alternative treatments for ADHD: 1) consuming caffeine and/or a diet of whole foods and no high fructose corn syrup, supplements including fish oil, B vitamins, and melatonin at night, 2) cultivating good habits or routines throughout the day that are accomplishment driven not time driven (i.e. "when you finish your breakfast, brush your teeth") and at night that are calming, 3) concentrating on what "to do" rather than what not to do, 4) therapies including occupational therapy and Eye Movement Desensitization and Reprocessing (EMDR) therapy, and 5) using "fidget toys" or sensory chair cushions.

Intervention ideas for children with $\mathrm{CP}$ were prompted by an adoptive mom from Maine's request for fun ideas to do with her two adopted children in the summer. The ideas 
provided by four other mothers were fun and entertaining activities to do with children with or without CP: swimming, Legos, making home videos, playing dress up, writing silly stories, board games, baking cookies, and arts and crafts (i.e., paper mache, coloring books, modeling clay, shaping and decorating Playdoh, making things out of duct tape, sculpting ornaments, and jewelry).

Two parents provided advice on intervening with children with Dyslexia. An adoptive mother of one from Texas advocated for the strengths perspective:

The biggest thing is to focus on his [my son's] strengths and let reading be not as important...it [Focusing on strengths] has helped him maintain his passion for learning to read despite the fact that it is hard for him. He still loves to read, and that is all that matters, the ability will catch up.

Another parent suggested that others read: Unlocking the power of print: A tutor practicum manual for teaching the Dyslexic reader.

Advice on intervening with children with FAS was provided by two adoptive mothers. Kandy, a mother of four, and Yasura, a mother of three, reported that strict adherence to rules and routines, balancing glucose, and peace were essential for their children. Kandy shared how her son exhibits the need for routine and glucose balance:

My tantrummer doesn't transition well, has difficulty with self-regulation, impulse control is an issue, AND he can't go too long between meals. Tantrums are sometimes exacerbated by the need to eat. "Irritability" is a sign of low blood sugar.... Often before dinner he's particularly easily annoyed, so we try to make sure that we eat on time then.

Yasura demonstrated that children with FAS need peace and quiet: "He [my son] said if my daughter is watching TV in the front room, and my husband is mowing the lawn, and my other son is in the garage lifting weights, and I am cooking or cleaning, it makes him crazy and he acts up to stop it."

Therapeutic approaches for PTSD were recommended by three parents. Recommendations included medications (i.e. Intunive and Clonodine) and therapies (i.e. neuropsychological therapy, art therapy, and EMDR). However, two mothers advocated that the therapeutic approach must address the underlying issues of PTSD rather than the symptoms. Nina explained, "I can't say that the therapy has helped much, no. The goals of therapy were to deal with things like her flashbacks, memory processing, hypervigilance etc. though. The symptoms you see in PTSD basically." Another mother, Tracy responded, "Until the root of the problem is identified and addressed, the individual can't change their behavior."

Parents of children with RAD discussed the struggles of parenting children who could often be manipulative, make bad choices, and whose anxiety could be easily triggered. Francine, an adoptive mother of one from Maine illustrated her daughter's manipulation: "I can see the 'wheels turning' all the time. I have to be one step ahead of her [my daughter] at all times." Cristina, another adoptive mother of one from Utah made a suggestion to deal with "bad choices" made by children with RAD, "The only real way to help them make 
better choices is by helping them meet their needs in the least destructive way possible." Mandy, an adoptive mother of three from California, demonstrated how much children with RAD need stability:

Redid [my son's] room. Painted it the colors he chose.... For five minutes he loved it. And then he hated it, and proceeded to meltdown for a few hours.... After which, we debriefed for a bit, and realized that having a whole new room reminded him of all the moves and families he's had to move to. And freaked him out.... only in our world does fresh paint result in a revisiting trauma!

\section{Education}

Four main themes of advice were given to parents pertaining to children having no interest in school, stigma and confidentiality, and the idea of "unschooling." Four parents reported that their children were not interested and sometimes refused to go to school. Two parents reported that it is normal for children to have a difficult time adjusting to $1^{\text {st }}$ grade and middle school. River, an adoptive mother of one and former teacher from Minnesota, suggested that parents ask teachers to give children who are uninterested in school a special task to help them to "gain a feeling of importance." A few parents were afraid to inform schools of their children's diagnoses, especially RAD, because their children would be treated differently and stigmatized. One parent noted that, because of HIPPA, parents only have to share what they want to share. Hannah suggested, "I would only share with the school what you are comfortable sharing. I have been told by a few counselors to "watch the labels' when it comes to school because it can come back to bite the child."

"Unschooling" is a method of homeschooling that does not use a predetermined curricula, but meets the students where they are and progresses in challenging the student to learn new material when they are ready. Four parents discussed using this method for children with various special needs. Kandy, a mother of four from Oregon who "unschools" her children explained her method:

We limit "class time" - the actual, sit down, write, read, pay focused attention time - during homeschool. We do a lot of reading out loud (them to me, me to them) and lots of hands on kinds of things. Games. Math games that the kids have made up, board games, actual "educational" games, online games like how to type (keyboarding skills). We LOVE documentaries and Netflix has bunches of them.

\section{Feature, Link, and Exchange Analysis}

The Forums.Adoption.com "Special Needs Adoption" sub-forum included 138 advertisements posted by the website administrators, 23 hyperlinks posted by members in discussion, and three members mentioned continuing their discussion in "personal messages" (PM). The advertisements were relevant to users, because all of them advertised adoption resources or organizations, such as "Adoption Community Information." The hyperlinks were posts as a part of member's signatures $(n=8)$ or as resources $(n=15)$ that they were providing to other members. Five of the hyperlinks used as signatures were links to the participants' blog while the others included links to websites on post-adoptive depression and the Church of the Latter Day Saints beliefs. Links posted as resources 
included school $(\mathrm{n}=8)$, dyslexia $(\mathrm{n}=2)$, dyspraxia $(\mathrm{n}=1)$, ADHD $(\mathrm{n}=1)$, medical $(\mathrm{n}=$ $2)$, and child cell phone $(\mathrm{n}=1)$ resources. Participants who mentioned using PM to continue discussions were referring to an instant messaging capability available on Forums.Adoption.com.

\section{Language Analysis}

The most common emotion word used in all themes was "hard" reflecting that parenting children with special needs was difficult. It was often used as an emotion, such as "it is hard." The language analysis resulted in 63 emotion words associated with disability issues. The majority of emotions were negative, such as "hard," while some suggested positivity, such as "joy." The disability-related emotion words are displayed in a Wordle (Feinberg, 2013), which shows more common words in larger, bolder text and less common words in smaller text (Figure 3). Seventeen emotion words were associated with intervention discussion. All words except three were negative (e.g., out of control). The positive words reflected outcomes that participants desired based on interventions, such as "control" and "better." Twenty-three emotion words were associated with empathy. The most common word was "hard." The only positive emotion word associated with empathy discussion was "awesome," which reflected a member's excitement for another member. Twenty emotion words were associated with placement issues. Emotion words reflected mixed emotions associated with placements. Discussion of school is associated with eleven emotion words; four were positive, such as "proud," while the rest were negative, such as "panic." Discussions of case worker issues were associated with 11 emotion words. All but one word were negative. Discussions of social support were associated with seven negative words, such as "hurt." Discussion of resources and lack of historical information were both only associated with four emotion words. Discussions of resources were associated with three positive words, such as "powerful" and one negative word, "anxiety." Discussions of lack of historical information were associated with all negative words, such as "helpless." Discussion of physiological versus psychological was only associated with one emotion word, "scary."

Figure 3. Disability Theme Wordle

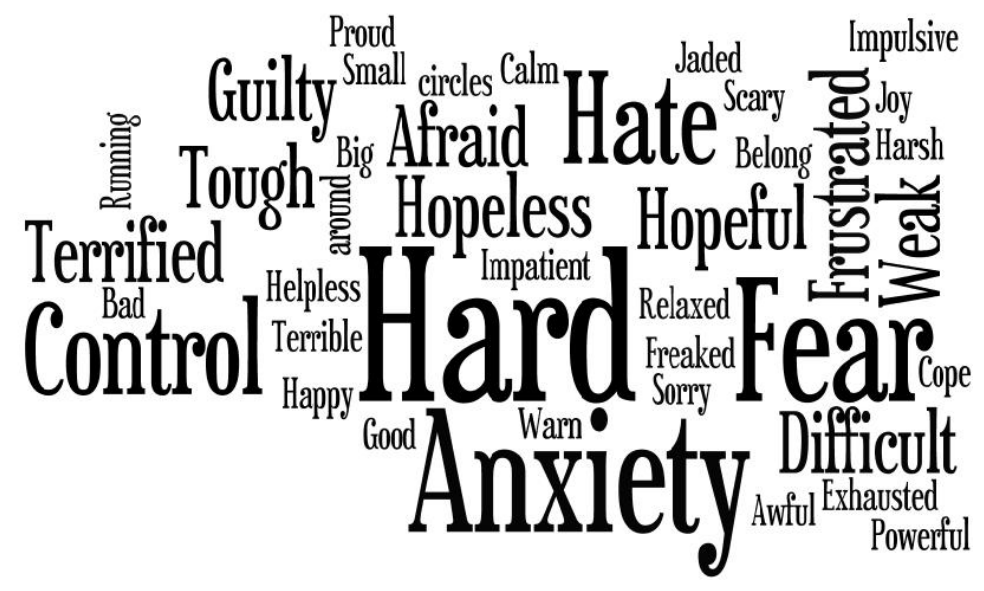




\section{SAFE Theoretical Framework}

The needs expressed by adoptive and foster parents of children with special needs are reflective of pre-placement and post-placement needs. The findings of this study are displayed in the SAFE Model (Figure 4), which shows that prior to a placement adoptive and foster parents need engagement and assessment including child welfare services, knowledge about the symptoms associated with the potential foster or adoptive child's diagnoses, and historical information about the child. After a child with special needs is placed with an adoptive or foster family, the family needs assessments and interventions including educational and neuropsychological testing and potential behavioral and educational interventions associated with the child's diagnoses.

Figure 4. SAFE Model

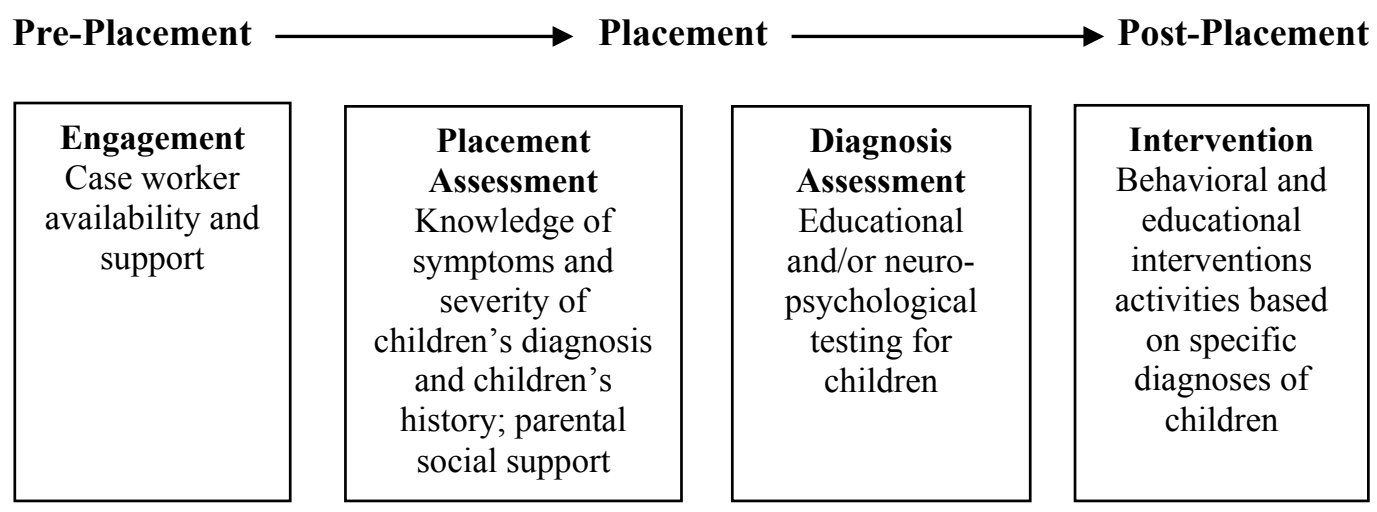

\section{Discussion}

The WCA of an online discussion forum of adoptive and foster parents of children with special needs identified that the topics of discussion on parenting concerns were clustered into two main themes, disability and placement issues, and focused on children's pre and post placement needs. Discussions of disability issues were statistically significantly correlated with discussions of intervention, school, and resources. Thus, adoptive and foster parents of children with special needs were concerned about and needed resources regarding interventions and school for their children. Discussions of resources were also associated with discussions of differentiating physiological versus psychological symptoms in children with special needs. Negative emotion words were primarily used during discussions in the disability cluster with the exception of mixed emotions associated with school and positive emotions associated with resources. Hyperlinks posted by participants provided resources for school and other disability-related or interventionrelated information. Discussions of placement issues were correlated with discussions of case workers, empathy, social support, and lack of historical information. Placement issues among adoptive and foster parents of children with special needs were statistically significantly correlated with case worker issues and not having information about children's history. In addition, parents' reports that they were experiencing social support issues, such as marital conflicts, were often reported in conjunction with discussions of placement issues. Thus, making placement decisions may have caused marital or social 
tension. The data also showed that participants primarily provided empathy for one another regarding placement issues. Mixed emotion words were used during discussions of placements, while negative words were primarily used in discussions of case workers, empathy, social support, and lack of historical information.

Adoptive and foster parents of children with disabilities need support in finding appropriate interventions and making choices regarding school for their children. This study shows that parents went to each other for advice regarding interventions and school issues. These are resources that child welfare case workers may be able to provide parents. As indicated by Manders and Stoneman (2009) child welfare case workers tend to refer families with children with disabilities to receive child-focused services. Child welfare case workers should receive training on disability diagnoses and possible interventions associated with disability diagnoses to increase the provision of mental health services to children with special needs. However, this study showed that parents not only needed interventions for their children, but also needed social support. Case workers should be aware that adoptive and foster parents may also need support. Participants in the study were quite critical of case workers. This may reflect the challenges experienced by case workers with large sample sizes and minimal resources due to budget cuts. This study may demonstrate the potential impact of budget cuts and increased caseloads among case workers. A recent study found that an additional $50 \%$ of case workers were needed to provide adequate in-home services to clients suggesting the minimal resources available in current child welfare agencies (Kaye, Shaw, DePanfilis, \& Rice, 2012).

This study showed that placement decisions among adoptive and foster parents relied on case workers, knowledge of children's history, and social support. Child welfare case workers can support adoptive and foster parents by being supportive of and available to them, providing as much history as possible about children, and counseling parents about any social support issues that they may be experiencing. In trainings, child welfare case workers should be informed of parent-focused interventions for parents of children with special needs. This information may need to be emphasized since case workers may tend to provide these families with information only about child-focused interventions (Manders \& Stoneman, 2009).

\section{Conclusion}

The SAFE Theoretical Model can inform child welfare workers of basic pre and post placement needs of adoptive and foster parents of children with special needs. The Model represents the rudiments of a plan to thoroughly understand and develop a comprehensive model that child welfare case workers can use to address the needs of adoptive and foster families of children with special needs. Future research is needed to further understand needs of adoptive and foster children with specific disabilities. In addition, application of the SAFE Model in practice may result in adaptations or revisions to the model based on context and translation. 


\section{References}

Algood, C. L., Hong, J. S., Gourdine, R. M., \& Williams, A. B. (2011). Maltreatment of children with developmental disabilities: An ecological systems analysis. Children and Youth Services Review, 33(7), 1142-1148.

Balog, K., Mishne, G., \& Rijke, M. (2006, April). Why are they excited? Identifying and explaining spikes in blog mood levels. Paper presented at the 11th Meeting of the European Chapter of the Association for Computational Linguistics, Trento, Italy.

Bean, K. F., \& Sidora-Arcoleo, K. (2012). The relationship between environment, efficacy beliefs, and academic achievement of low-income African American children in special education. Journal of Social Work in Disability \& Rehabilitation, 11(4), 268-286.

Geenen, S., \& Powers, L. E. (2004). Are we ignoring youths with disabilities in foster care? An examination of their school performance. Social Work, 51(3), 233-241.

Feinberg, J. (2013). Wordle [Computer software]. Retrieved from http://www.wordle.net/

Herring, S. C. (2010). Web content analysis: Expanding the paradigm. In J. Hunsinger, L. Klastrup, \& M. Allen (Eds.), The international handbook of Internet research (pp. 233-249). Dordrecht, Netherlands: Springer Netherlands.

Hill, K. (2012). Permanency and placement planning for older youth with disabilities in out-of-home placement. Children and Youth Services Review, 34(8), 1418-1424.

Jonson-Reid, M., Drake, B., Kim, J., Porterfield, S., \& Han, L. (2004). A prospective analysis of the relationship between reported child maltreatment and special education eligibility among poor children. Child Maltreatment, 9(4), 382-394.

Kaye, S., Shaw, T. V., DePanfilis, D., \& Rice, K. (2012). Estimating staffing needs for in-home child welfare services with a weighted caseload formula. Child Welfare, 91(2), 61-76.

Krippendorff, K. (2008). Testing the reliability of content analysis data: What is involved and why. In K. Krippendorff \& M. A. Bock (Eds.), The content analysis reader (pp. 350-357). Thousand Oaks, CA: Sage Publications.

Lightfoot, E., Hill, K., \& LaLiberte, T. (2011). Prevalence of children with disabilities in the child welfare system and out of home placement: An examination of administrative records. Children and Youth Services Review, 33(11), 2069-2075.

Linton, K. F., Krcek, T. E., Sensui, L. M., \& Spillers, J. L. H. (2013). Opinions of people who self-identify with Autism and Asperger's on DSM-5 criteria. Research on Social Work Practice. doi:10.1177/1049731513495457

Manders, J. E., \& Stoneman, Z. (2009). Children with disabilities in the child protective services system: An analog study of investigation and case management. Child Abuse \& Neglect, 33(4), 229-237. 
Nimrod, G. (2009). Seniors' online communities: A quantitative content analysis. The Gerontologist, 50(3), 382-392.

Orme, J. G., \& Gillespie, D. F. (1986). Reliability and bias in categorizing individual client problems. The Social Service Review, 60(1), 161-174.

Orwin, R. G. (1994). Evaluating coding decisions. In H. Cooper \& L. V. Hedges (Eds.), The handbook of research synthesis (pp. 139-162). New York, NY: Russell Sage Foundation.

Padgett, D. K. (2008). Qualitative methods in social work research. Thousand Oaks, CA: Sage Publications.

Raghavan, R., Inoue, M., Ettner, S. L., Hamilton, B. H., \& Landsverk, J. (2010). A preliminary analysis of the receipt of mental health services consistent with national standards among children in the child welfare system. American Journal of Public Health, 100(4), 742-749.

Ryan, G. W., \& Bernard, H. R. (2003). Techniques to identify themes. Field Methods, 15, 85-109.

Slayter, E., \& Springer, C. (2011). Child welfare-involved youth with intellectual disabilities: Pathways into and placements in foster care. Intellectual and Developmental Disabilities, 49(1), 1-13.

Sullivan, P. M., \& Knutson, J. F. (2000). Maltreatment and disabilities: A populationbased epidemiological study. Child Abuse \& Neglect, 24(10), 1257-1273.

Viera, A. J., \& Garrett, J. M. (2005). Understanding interobserver agreement: The kappa statistic. Family Medicine, 37(5), 360-363.

Yoon, Y., Rubin, D. M., Riddle, M. A., Noll, E., \& Rothbard, A. (2011). Antipsychotic treatment among youth in foster care. Pediatrics, 128(6), e1459-e1466.

\section{Author note}

Address correspondence to: Kristen F. Linton, MSW, Ph.D., Myron B. Thompson School of Social Work, University of Hawai'i, 1800 East West Road, Honolulu, HI 96822, kfbean@asu.edu 